\title{
MICROSTRUCTURE COMPARISON OF HIGH STRENGTH INCONEL 718 NUTS
}

\author{
Daniel P. Dennies, Ph.D. \\ The Boeing Company \\ 5301 Bolsa Avenue, Mail Code H021-F224 \\ Huntington Beach, California 92647
}

\begin{abstract}
The industry specifications for nuts and fasteners usually only specify hardness and strength requirements. For the majority of these specifications there are no controls for the microstructure, especially grain boundary precipitates. Various fabrication processes are employed by different suppliers to produce the same nut or bolt. This paper compares the microstructure of a high strength Inconel 718 nut produced by two different suppliers and comments on the microstructures exhibited.
\end{abstract}




\section{Introduction}

One of the most difficult failure investigations to perform concerns delayed failure. In the spring of 2000, a 220-ksi strength Inconel 718 nut was found to have failed sometime after installation. The fractured nut was discovered when part of an expendable launch vehicle static fire test structure was requested from a Boeing storage facility, approximately 4 months after nut installation. Upon removal of the assembly from storage, one of the 16 installed nuts was discovered to have split in half.

The Boeing designed nut is a $0.625-18$ nut with an UNJF-3B thread per MIL-S-8879 and a selflocking feature. It is 0.692 in. tall, $1.062 \mathrm{in}$. in diameter at the base, $0.882 \mathrm{in}$. in diameter at the points of the 12-point area, and has a minimum ultimate tensile strength of $59,820 \mathrm{lb}$. The nut is usually fabricated from a material specification of the fastener company, but the basic material specification is AMS 5662. The nut was discovered split in half with one half still on the bolt, and missing a small triangular piece near the top of the nut in the area of the self-locking feature (Figure 1).

This failure was interesting for two reasons. One, in fastener systems, it is more common for the bolt to fail than the nut. And two, the nut was split completely in half, not just fractured on one side. The exact clocking of the nut position on the bolt could be determined by the torque stripe markings, which were applied when the nut was installed (Figure 1).
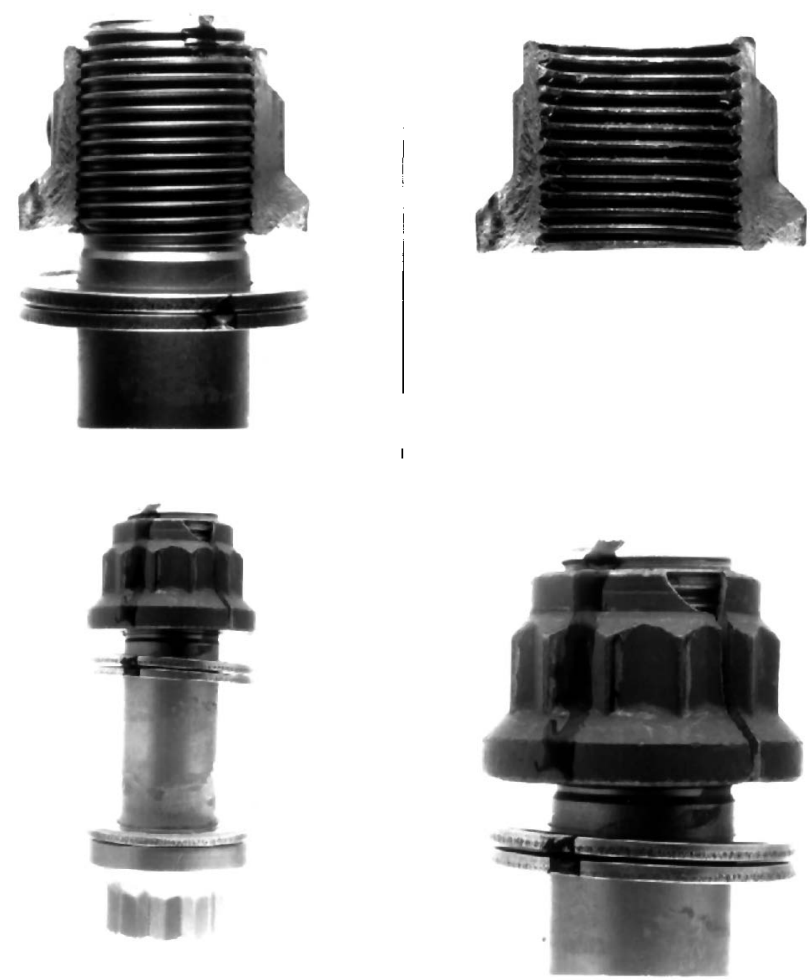


\section{Failure Analysis}

The Material and Process Engineering Department at the Boeing Huntington Beach facility was requested to perform a failure analysis.

\section{Fracture Surface Examination}

Examination of the fracture surfaces using light microscopy and the scanning electron microscope revealed that approximately $95 \%$ of the fracture occurred in a ductile overload (Figure $2 \mathrm{~A}$ ). The chevron pattern in the overload area pointed toward the base area of the nut indicating a potential initiation site (Figure 2D). The remaining 5\% of the fracture surface displayed a "rock candy" appearance that was a mixture of intergranular and quasi-cleavage, characteristic of a brittle mode of failure (Figure 2B). This area occurred at the base of the nut along the inner diameter and was approximately 0.06 by 0.13 in. in size (Figure 2D). This small area near the base of the nut, penetrating about 0.010 in. into the intergranular/quasi-cleavage fracture surface, contained another area that was covered with a contaminant (Figure $2 \mathrm{C}$ ).

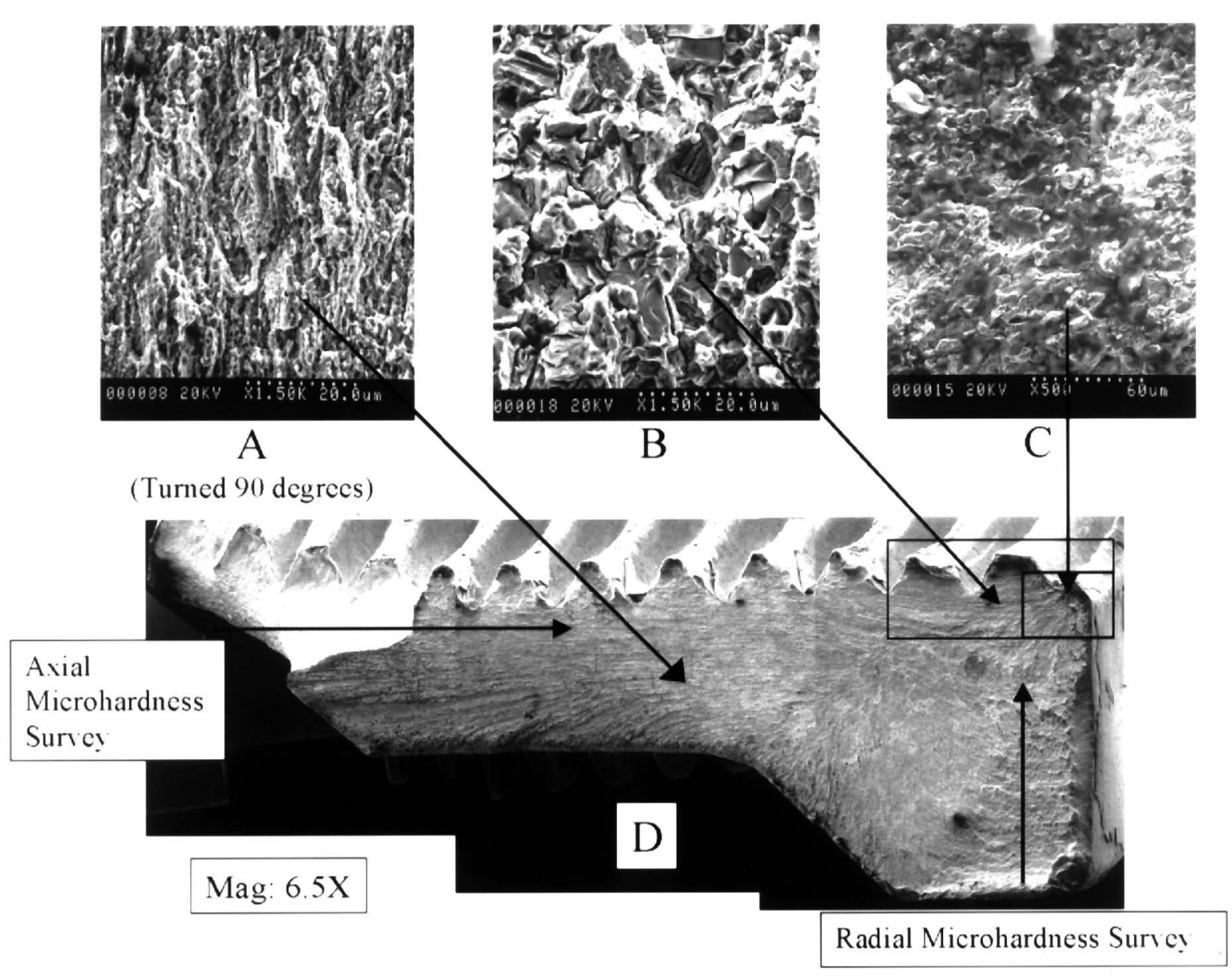

Figure 2: Fracture Surface of Split Inconel 718 Nut

\section{Microhardness Survey}

As part of the failure analysis, an axial and radial microhardness survey was performed on an axial cross section of the failed nut. To determine if the failed nut was in some way different than other nuts, a comparison was made to nuts from the same lot of the same vendor. In addition, a second lot from the vendor was tested. To further randomize the nut population, nuts 
from both these lots were obtained from two different Boeing facilities. Lastly, nuts from two different lots of a second vendor were also tested. The axial microhardness survey was performed just outside of the thread roots in order to be able to extend from the top to bottom of the nut (Figure 2D). The radial microhardness test was performed at the first thread crest from the bottom of the nut (Figure 2D).

The drawing requirement for hardness of the nut is $R_{c} 50$ maximum. A microhardness test with a Knoop hardness of approximately 542 correlates to $R_{c} 50$. Examination of the graph of the axial microhardness surveys of the nuts indicates a rather close grouping of the hardness data for all the nuts tested (Figure 3). It should be noted that four of the nuts were higher than the $R_{c}$ 50 maximum criteria and the balance of the nuts are very close, ranging in value between $R_{c} 47$ to 50 . The failed nut does not violate the $R_{c} 50$ maximum hardness criteria.

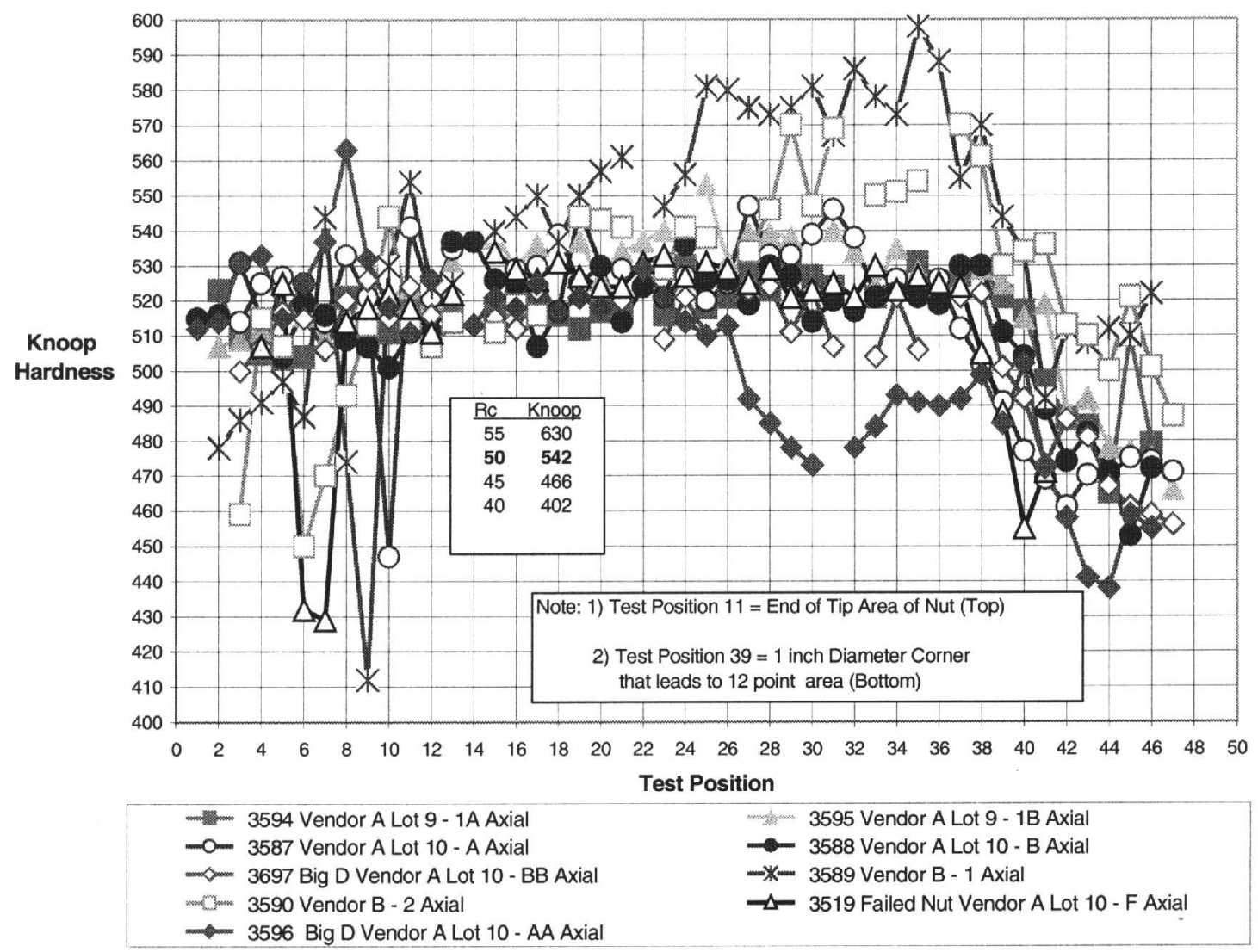

Figure 3: Inconel 718 Nut Failure Axial Microhardness Surveys

There is also a trend for the hardness to drop in the thicker base section of the nut below the 12 point area, as noted in test positions 38-47. The range of hardness values in the base area was approximately $\mathrm{R}_{\mathrm{c}} 42-48$.

The two nuts that are well above the $R_{c} 50$ hardness criteria are from Vendor $B$. The two nuts from Vendor B and the failed nut from Vendor A also drop in hardness toward the top of the nut in test positions 2-10. No explanation was found to explain the erratic low data in test positions 26-38 for the nut labeled 3596 Big D Vendor A Lot 10.

The radial microhardness surveys of the nuts also indicated a rather close grouping of the hardness data for all the nuts tested, ranging in value between $R_{c} 42$ to 48 (Figure 4). This data closely matches the axial microhardness survey data taken in the same area, test position 46 . 


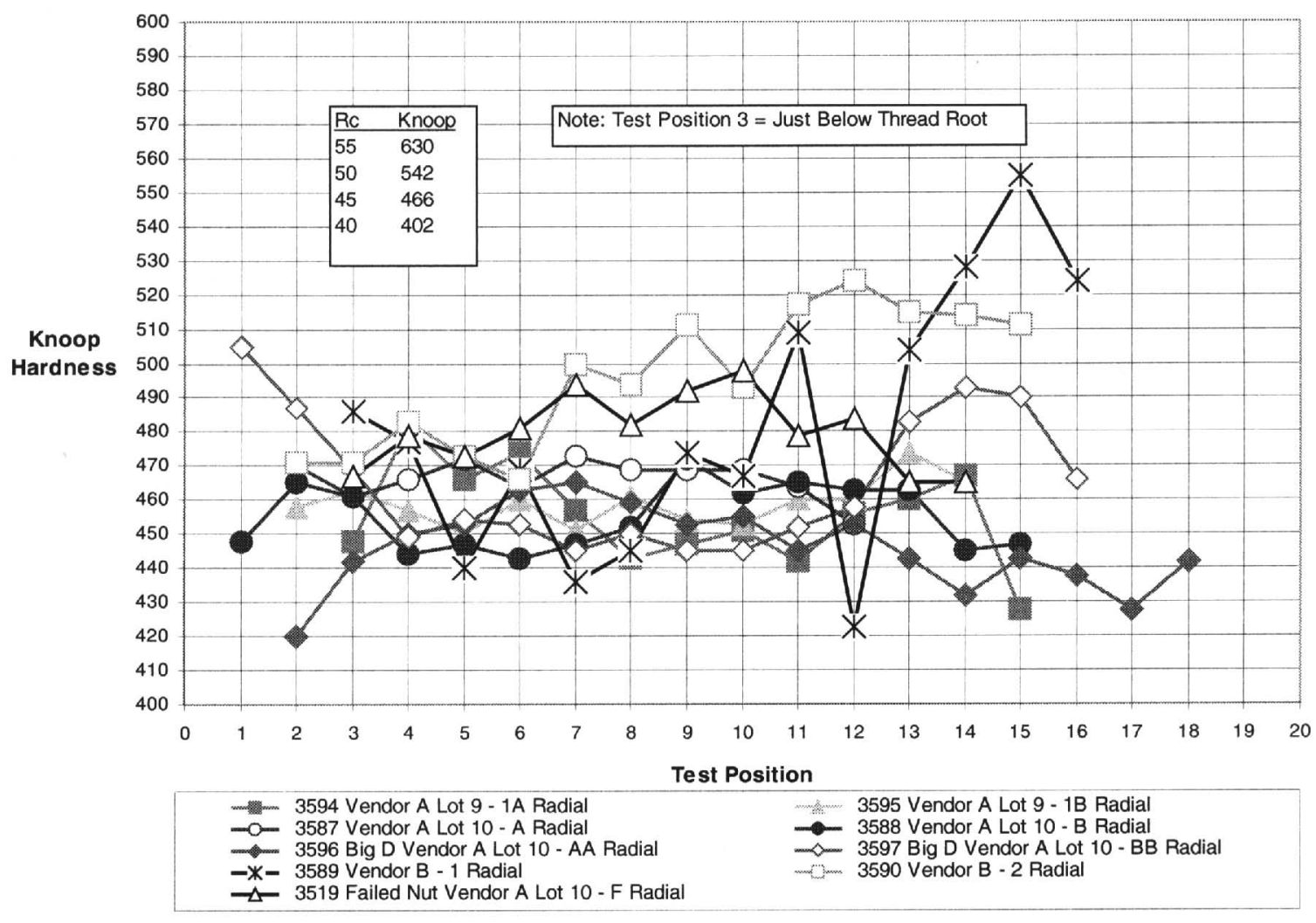

Figure 4: Inconel 718 Nut Failure Radial Microhardness Surveys

In a similar manner as the axial microhardness survey, the two nuts from Vendor B exhibited the most variation and the highest hardness values. The nut from lot Vendor B-1 (lot one) violated the $R_{c} 50$ maximum criteria once toward the outside diameter of the base of the nut.

\section{Chemical Composition}

The chemical composition for the nuts used in the microhardness surveys was compared and found to be the same. A statistical analysis was performed, and the standard deviations calculated were extremely low. The nuts from Vendor B, which demonstrated the higher hardness values, did not exhibit any abnormal variation from the average.

\section{Metallographic Examination}

A metallographic examination was performed on each of the nuts used in the microhardness surveys. Differences were noted between the microstructure of the nuts from Vendor A and Vendor B.

The microstructures of the nuts from the two lots from Vendor B were very similar. Both lots exhibited equiaxed grains with a grain size of $4-5$ at the top and the base of the nut as well as along the threaded area of the inside diameter (Figure 5). The nuts also exhibited what appeared to be thermo-mechanically processed (TMP) grains in the 12-point area of the nut. The TMP, or "warm-worked," grains exhibited a slightly finer grain structure and were more feathery in appearance with aspect ratios as high as four to one (Figure 6). Neither the equiaxed grains nor the TMP grains exhibited any grain boundary precipitation. 

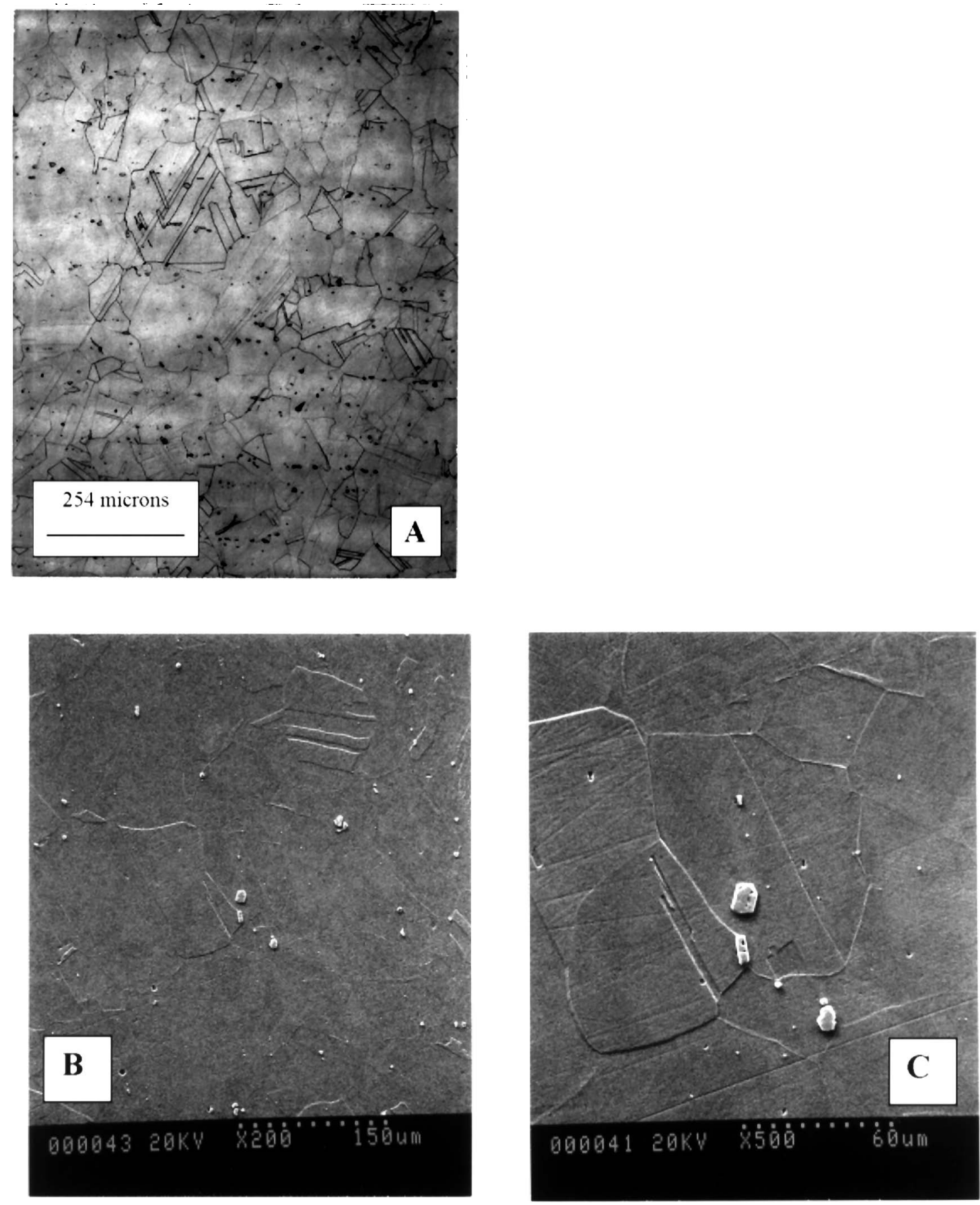

A) Metallographic Photomicrograph - Mag: 100x

B) SEM Photograph - Mag: 200x

C) SEM Photograph - Mag: 500x

Note: 1) Equiaxed Grain Size of 4-5

2) No Grain Boundary Precipitates

Figure 5: Vendor B Lot 1 Equiaxed Grains 

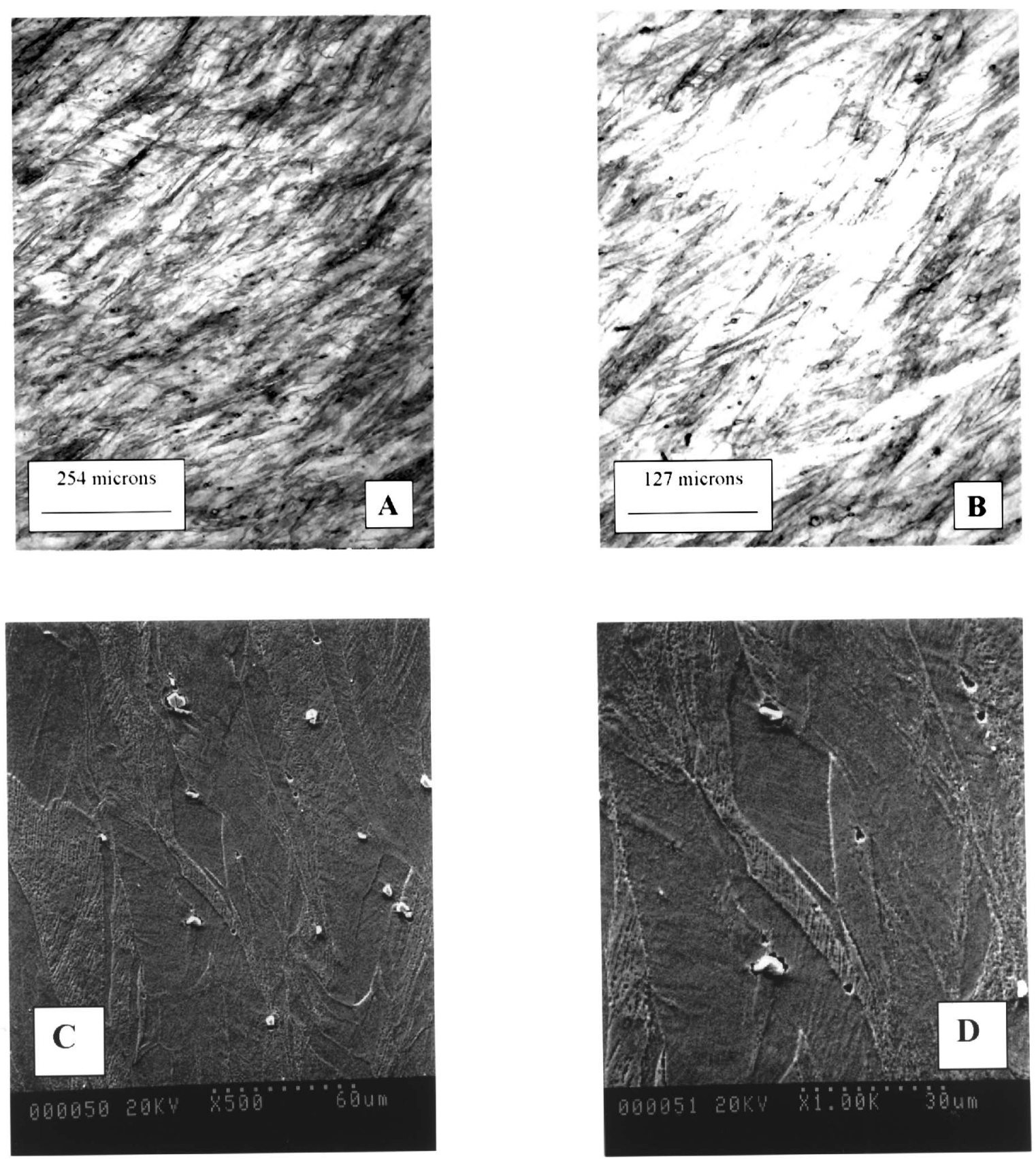

A) Metallographic Photomicrograph - Mag: 100x

B) Metallographic Photomicrograph - Mag: 200x

C) SEM Photograph - Mag: 500x

D) SEM Photograph - Mag: 1000x

Note: 1) "Warm-Worked" Grain Structure

2) No Grain Boundary Precipitates

Figure 6: Vendor B Lot 1 TMP Grains 
In contrast, the microstructures for the nuts from the two lots from Vendor A were very different than the microstructures for the nuts from the two lots from Vendor B.

First, the distribution of the type of grain structure along the length of the nut was different. Both lots from Vendor A exhibited equiaxed grains at the top and the base of the nut as Vendor $B$, but the area of equiaxed grains was smaller and did not extend along the threaded area of the inside diameter.

Second, the equiaxed grains in the nuts from Vendor $A$ were also much finer than the equiaxed grains in the nuts from Vendor B. Vendor A lot 9 exhibited an approximate grain size of 10, and Vendor A lot 10, including the failed nut, exhibited an approximate grain size of 12 (Figure 7).

Third, the equiaxed grains in the nuts from Vendor A exhibited a significant amount of discrete, incoherent grain boundary precipitate, most probably a combination of platelet and globular Delta phase. In many areas there was a semi-continuous network along the grain boundaries (Figure 7).

Fourth, the nuts from Vendor A did not exhibit the TMP grains in the 12-point area of the nut as noted in Vendor B, but instead exhibited a very fine and severely cold-worked microstructure (Figure 8 ). The very fine and severely cold-worked microstructure exhibited a higher volume percentage of the discrete, incoherent grain boundary precipitates than the equiaxed grains noted previously (Figure 8).

The increased amount of grain boundary precipitates was not a surprise. It is well known that a cold-worked condition in nickel base and nickel-iron base superalloys accelerates the reaction kinetics of the precipitation aging mechanism. Closely related to this information is that high strength nuts and bolts are fabricated from cold-worked material.

The discrete, incoherent grain boundary phases are most likely a combination of platelet and globular Delta phases, as noted in the equiaxed grains. However, there may also be some Laves phase. Laves phase has been demonstrated to be found in Inconel 718 wrought material that has had large amounts of cold work (1).

\section{Manufacturing Process}

The manufacturing process of Vendor $\mathrm{A}$ was reviewed. It was discovered that the bar stock used to make the nuts had been subjected to over $50 \%$ cold work to form the 12 -point area of the nut in one manufacturing step. In addition, the two-step precipitation aging heat treatment of the nut included a higher than industry standard precipitation aging temperature in the first step. The higher first step precipitation aging temperature was employed to overage the microstructure in the 12-point area of the nut and produce a hardness that would conform to the drawing requirement of $R_{c} 50$ maximum.

The manufacturing process of Vendor B was not reviewed. However, the similarity of the chemical composition combined with the differences in the microhardness surveys and microstructures lead to the conclusion that the manufacturing procedures used by Vendor $\mathrm{B}$ are not the same as Vendor A. 

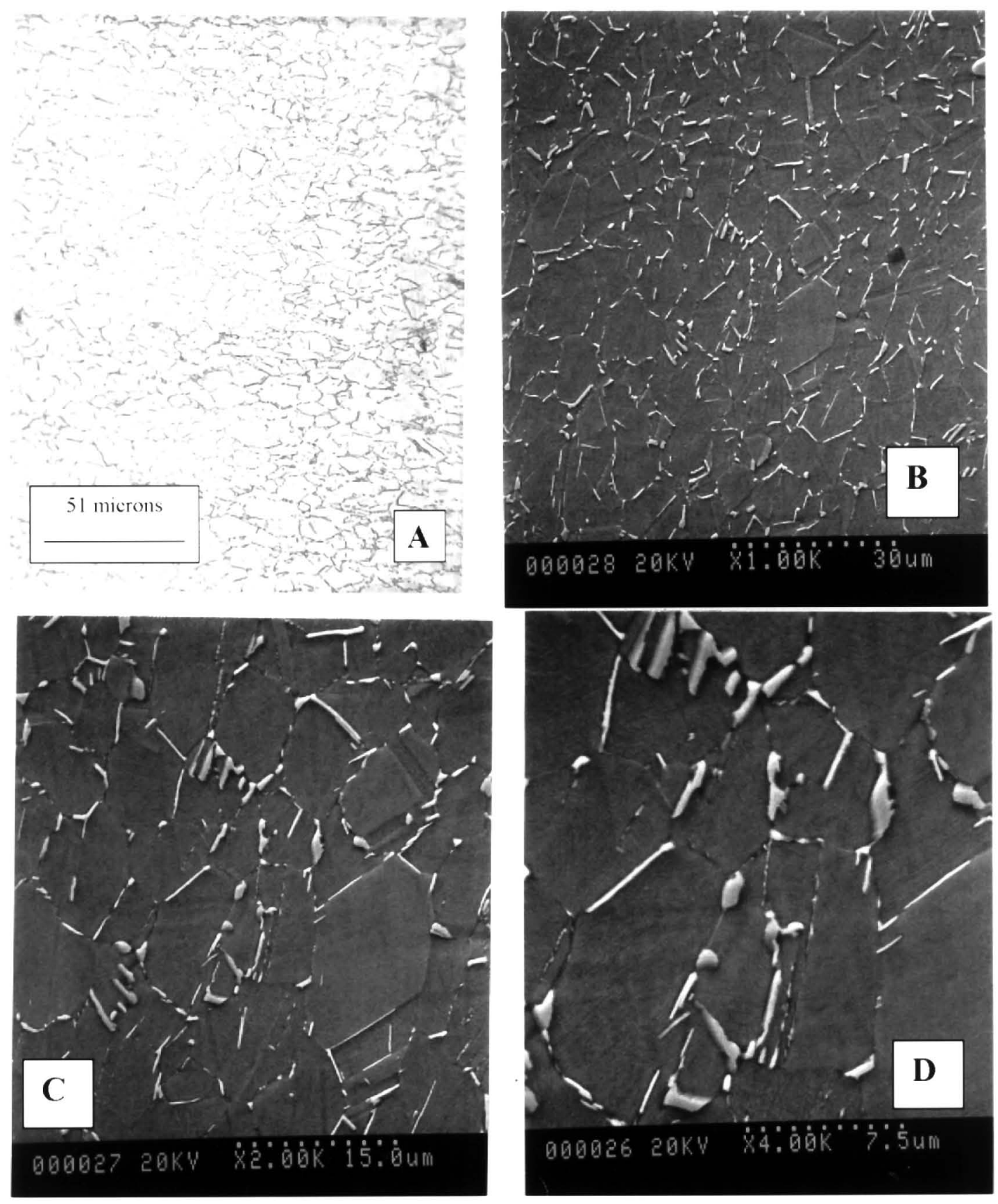

A) Metallographic Photomicrograph - Mag: 500x

B) SEM Photograph - Mag: 1000x

C) SEM Photograph - Mag: 2000x

D) SEM Photograph - Mag: 4000x

Note: 1) Equiaxed Grain Size of 12

2) Grain Boundary Precipitates

Figure 7: Vendor A Lot 10 Equiaxed Grains 

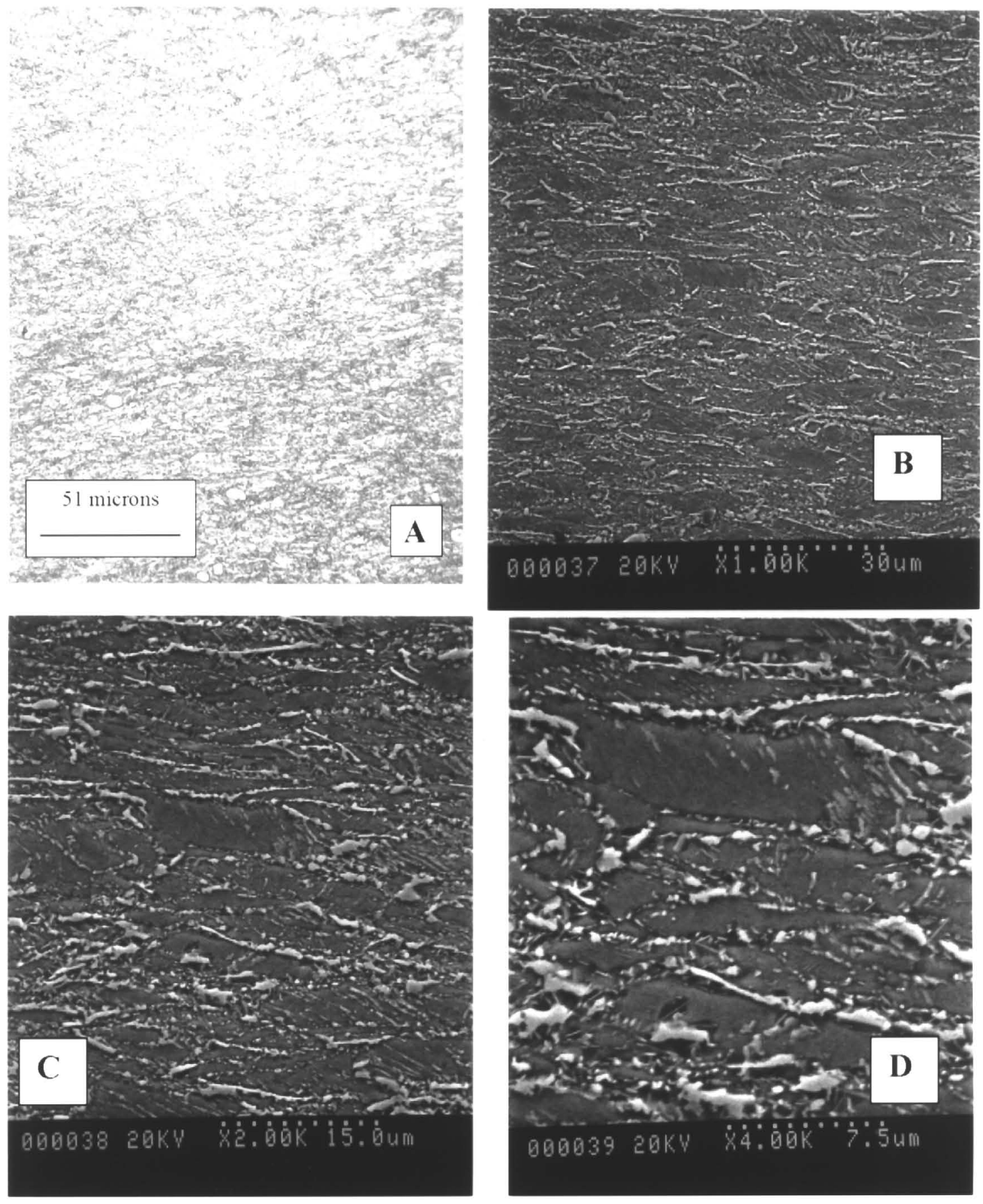

A) Metallographic Photomicrograph - Mag: 500x

B) SEM Photograph - Mag: 1000x

C) SEM Photograph - Mag: 2000x

D) SEM Photograph - Mag: 4000x

Note: 1) Cold --Worked Grain Structure

2) Grain Boundary Precipitates

Figure 8: Vendor A Lot 10 Cold-Worked Grains 


\section{Results}

The failure investigation of the split Inconel 718 nut confirmed that the failure originated at an area located along the base of the nut near the inside diameter. Examination of the initiation area revealed a brittle mode of failure that is uncharacteristic of this material. Comparison of the microhardness survey and microstructure of various nuts in combination with a review of the manufacturing processes employed to fabricate the nuts revealed differences in the nuts.

The failure investigation of the split Inconel 718 did not determine a single root cause for the failure. However, the microstructure exhibited in the material was considered to be a significant factor in many of the root causes noted in the fault tree. A high volume percentage of discrete, incoherent grain boundary precipitates, especially a semi-continuous network, is detrimental to the mechanical properties of Inconel 718, as it would be to most any alloy. In general, the effect of this grain boundary network in the microstructure is undesirable because it will reduce the ductility of the material.

There are many mechanisms in which a high volume percentage of discrete, incoherent grain boundary precipitates can affect mechanical properties including brittle fracture through the precipitate, brittle fracture at the interface of the precipitate and the matrix, and depletion of the matrix of an alloying element required for another purpose such as precipitation aging or corrosion resistance. Previous work has noted that a room temperature tensile sample can break with 100\% intergranular fracture when the microstructure had a grain boundary precipitate network in the form of Laves phase (2).

In addition, grain boundary precipitates can make a material more susceptible to environmentally assisted cracking (EAC) failures by dropping the surface energy of the interface between the discrete, incoherent precipitates and the matrix. Some examples of EAC failures to which the grain boundary precipitates can make a material more susceptible include sulfur embrittlement, hydrogen embrittlement, or "poisoning" by sulfur-hydrogen cosegregation embrittlement (3).

All nuts from lot 10 of Vendor A were purged from the Boeing inventory system and impounded.

\section{Conclusions}

Current nut and fastener specifications or drawings contain only hardness and tensile strength requirements. Very few contain any requirements concerning the microstructure of the material, especially grain boundary precipitates. Fastener and nut manufacturers are free to develop any combination of manufacturing and heat treatment steps necessary to produce the required hardness and tensile strength.

It is time to include a microstructure requirement in these specifications that prohibits the presence of any, or at least excessive, grain boundary precipitates, as demonstrated in this paper. The primary concern is the high strength nuts and fasteners using cold-worked material. An evaluation of other nuts and fasteners should be performed to determine if an issue exists concerning grain boundary precipitates. 


\section{References}

1. A. Oradie-Basile and J.F. Radavich, "A Current T-T-T Diagram for Wrought Alloy 718," Proceedings of the International Symposium on the Metallurgy and Applications of Superalloys 718,625 and Various Derivatives, ed. Edward Loria, (sponsored by TMS, ASMI and NACE, June 1991), 325-335.

2. J.J. Schirra, R.H. Caless, and R.W. Hatala, "The Effect of Laves Phase on the Mechanical Properties of Wrought and Cast + HIP Inconel 718," Proceedings of the International Symposium on the Metallurgy and Applications of Superalloys 718,625 and Various Derivatives, ed. Edward Loria, (sponsored by TMS, ASMI and NACE, June 1991), 375 388.

3. D.H. Lassila and H.K. Birnbaum, "Intergranular Fracture of Nickel: The Effect of

Hydrogen-Sulfur Co-Segregation," Acta metall, Vol. 35, No. 7, (1987), 1815-1822. 